\title{
Sobre o Processo de Elaboração de Atividades Matemáticas com o GeoGebra 3D
}

On the Process of Conceiving Mathematical Tasks using the GeoGebra 3D

\author{
Ricardo Scucuglia R. da Silva ${ }^{1}$ \\ Vinicius Honorato ${ }^{2}$
}

\section{Resumo}

Neste artigo discutimos o processo de elaboração de atividades matemáticas baseadas no uso do GeoGebra 3D. As atividades, concebidas enquanto produtos educacionais, foram criadas por integrantes de um grupo de pesquisa em Educação Matemática visando sua utilização em um curso de extensão universitária destinado a professores e futuros professores de Matemática. O processo criativo nesse cenário, conduzido e analisado de um ponto de vista qualitativo, envolveu questões como: (1) design da atividade: aspectos acerca do caráter (investigativo) e da audiência; e (2) uso de tecnologias digitais e pensamento matemático: visualização e experimentação-comtecnologias. Os resultados do presente estudo contribuem com aspectos prospectivos no que se refere ao uso de tecnologias digitais em Educação Matemática em um cenário de formação inicial e continuada de professores de Matemática na exploração de conteúdos de Geometria com o uso do software GeoGebra.

Palavras-chave: Educação Matemática. Ensino. Geometria Espacial.

\section{Abstract}

In this article we discuss the process of elaborating mathematical tasks regarding the use of GeoGebra 3D. The tasks, conceived as educational products, were created by members of a research group in Mathematics Education for its use in knowledge mobilization course for pre-service and in-service mathematics teachers. The creative process in this scenario, conducted and analyzed from a qualitative point of view, involved issues such as: (1) design of the activity: aspects about (investigative) design and

${ }^{1}$ Professor Assistente do Departamento de Educação do Instituto de Biociências, Letras e Ciências Exatas da Universidade Estadual Paulista (UNESP), campus São José do Rio Preto. Docente do Programa de Pós-graduação em Educação Matemática da UNESP, campus Rio Claro. Integrante do Grupo de Pesquisa, outras Mídias e Educação Matemática (GPIMEM).

${ }_{2}^{2}$ Mestrando em Educação Matemática pelo Programa de Pós-graduação em Educação Matemática da UNESP, campus Rio Claro. Tutor presencial - CEDERJ - polo Angra dos Reis, RJ. 
audience; and (2) use of digital technologies and mathematical thinking: visualization and experimentation-with-technologies. The results of this study contribute to prospective aspects regarding the use of digital technologies in Mathematics Education in a scenario of mathematics teacher education towards the exploration of Geometry with the use of software GeoGebra.

Key words: Mathematics Education. Teaching. Spatial Geometry.

\section{Introdução}

O conjunto de atividades matemáticas discutidas neste artigo, concebidas enquanto produtos educacionais estão disponíveis para download em http://igce.rc.unesp.br/gpimem. Trata-se de uma coleção de sete tarefas matemáticas elaboradas por integrantes do Grupo de Pesquisa em Informática, outras Mídias e Educação Matemática (GPIMEM) em 2016. As atividades foram criadas com o objetivo inicial de serem utilizadas em um curso de extensão universitária sobre geometria (dinâmica) e performance digital com base na utilização do software GeoGebra.

O curso, realizado na Universidade Estadual Paulista, Campus de Rio Claro, foi destinado a professores e futuros professores de Matemática e teve carga horária de dezoito horas. As tarefas matemáticas produzidas neste estudo estão estruturadas da seguinte maneira:

- Atividade 1: Triângulo Equilátero e Tetraedro Regular

- Atividade 2: Reta de Euler e Circunferência de Nove Pontos

- Atividade 3: Diagonais do Cubo

- Atividade 4: Construções Geométricas no Espaço

- Atividade 5: Interseção entre Planos e Poliedros

- Atividade 6: A Quadratura do Círculo - Método de Ernest Hobson

- Atividade 7: Prismas

Por uma opção metodológica, enfocamos em nossas discussões aspectos específicos sobre uma dessas atividades, a qual explora conteúdos de 
Geometria Espacial com o uso do GeoGebra 3D (Atividade 5). As discussões fundamentais acerca dessa atividade são também significativas a todas as outras atividades elaboradas na pesquisa. Metodologicamente, portanto, trabalhamos nesta situação com a noção denominada amostragem por julgamento (MARSHALL, 1996, p. 523), na qual "o pesquisador seleciona ativamente a amostra mais produtiva para responder à questão da pesquisa".

A realização do referido curso de extensão universitária foi cenário de investigação para o desenvolvimento de três pesquisas em nível de mestrado. A primeira delas, discutida neste artigo, investigou o processo de elaboração das atividades matemáticas para o curso por parte dos pesquisadores ${ }^{3}$. Para isso, a produção de dados ocorreu por meio de:

(a) registros em vídeo e diário de campo das reuniões ocorridas entre os pesquisadores-autores. Foram realizadas seis reuniões de aproximadamente uma hora de duração cada. O grupo foi formado por quatro integrantes, sendo um docente-orientador de pós-graduação e três alunos de mestrado em Educação Matemática. Referimo-nos a esses sujeitos como pesquisadores-autores;

(b) registros de interações online a distância (Facebook) em um grupo criado pelos quatro pesquisadores para discussão acerca da criação das atividades. Insights e ações individuais, bem como sugestões e solicitações eram compartilhadas por estes quatro pesquisadores no ambiente online;

(c) registros em vídeo e diários de campo de discussões de versões das atividades matemáticas em reuniões com demais integrantes do GPIMEM. Foram realizadas duas sessões de aproximadamente uma hora cada com a participação de aproximadamente trinta integrantes;

(d) registro digital de todas as versões das atividades matemáticas, desde sua concepção inicial, passando por todos os aprimoramentos qualitativos, até sua publicação para uso no curso de extensão universitária.

${ }^{3}$ A segunda pesquisa investigou a exploração das atividades durante o curso. A terceira pesquisa explorou questões acerca da produção de performances matemáticas digitais. 
Ao longo deste artigo apresentamos dados provenientes dessas fontes, como trechos de transcrições das reuniões, para expressar falas dos participantes, e imagens e citações das atividades. Por razões éticas, optamos em manter o anonimato na identificação das transcrições.

\subsection{Sobre o uso de Tecnologias Digitais e a Elaboração de Atividades Matemáticas}

O software GeoGebra é, provavelmente, o maior sucesso tecnológico da Educação Matemática na atualidade. Desde o início dos anos 2000's, o caráter multiplataforma e as potencialidades dessa tecnologia digital têm fomentado a contínua emergência de novos tipos de atividades matemáticas (dinâmicas), as quais permitem nuances diferenciadas de pensamento matemático em cenários de ensino e aprendizagem.

Mais recentemente, o lançamento das janelas e ferramentas tridimensionais do GeoGebra tem potencializado igualmente a elaboração de novas atividades para a constituição de cenários de investigação matemática. Neste artigo discutimos resultados de uma pesquisa cujo objetivo foi investigar o processo de elaboração de atividades matemáticas para exploração de conteúdos de Geometria (Espacial) com o GeoGebra. As atividades matemáticas elaboradas são concebidas neste cenário enquanto produtos educacionais.

Por um lado, destacamos o caráter dialógico-coletivo característico do processo de elaboração da atividade, visto que analisamos registros em vídeo de interações de um grupo de alunos e professor de pós-graduação que elaboraram atividades para um curso de extensão universitária destinado a professores e licenciandos em Matemática.

Nesse contexto, algumas de nossas inquietações foram: Como ocorreu o processo de elaboração das atividades? Que critérios e encaminhamentos didáticos e pedagógicos foram propostos e discutidos? Que decisões 
significativas foram tomadas com base em pressupostos teóricos-metodológicos? Quais eram esses pressupostos?

Por outro lado, é importante destacar a intensidade epistemológica do referido cenário de elaboração de tarefas, o qual fundamentou-se nas seguintes concepções: cenários de investigação matemática (PONTE; BROCADO; OLIVEIRA, 2003), experimentação com tecnologias (BORBA; SCUCUGLIA; GADANIDIS, 2014) e visualização (LEMOS; BAIRRAL, 2010).

De acordo com Borba, Scucuglia e Gadanidis (2014), a noção de experimentação-com-tecnologias baseia-se na utilização de tecnologias digitais no estudo de conceitos matemáticos. Abordada por Borba e Villarreal (2005), os autores ressaltam que essa perspectiva vai além de "apertar teclas". A exploração das potencialidades de uma tecnologia digital educacional dentro de um ambiente de experimentação (matemática) deve estar ligado a generalização e formulação de conjecturas, com a coordenação de múltiplas representações, com tentativas, análise de erros e com demonstração ou prova matemática (BORBA; VILLARREAL, 2005).

As tentativas e erros dentro de uma abordagem de experimentação acontecem não de forma aleatória, mas baseados no feedback gerado pelas tentativas e generalizações anteriores (BORBA; SCUCUGLIA; GADANIDIS, 2014). Quando se trata da utilização de uma tecnologia, este feedback se torna mais rápido, devido a possibilidade da exploração de diversos exemplos, o que impulsiona a forma com que o estudante interpreta e age diante suas tentativas e erros. Nessa perspectiva, uma característica que surge como importante das atividades trabalhadas é o caráter aberto, o qual exploraremos mais adiante.

A elaboração e discussão de atividades matemáticas foram foco de pesquisas como as de Gorgorió et al. (2000) e também de Nunes (2011). Ambas pesquisas indicam a necessidade da reflexão de grupos de pesquisa acerca da elaboração de atividades. Gorgorió et al. (2000) utilizaram a Geometria como tema central para suas atividades e contaram com a participação de especialistas renomados que contribuíram para o desenvolvimento das atividades. 
Inicialmente, os autores não desejavam apresentar as atividades ao público, mas sim, conhecer apenas como se dava o processo de elaboração e avaliação do material produzido. Porém, após as reflexões de elaboração, as atividades foram trabalhadas com alunos do Ensino Fundamental. Visando a análise de estratégias de pensamento, os autores levaram em conta o processo de resolução do aluno, desde o ponto de vista ao tipo de representação mental utilizada.

Os autores também possuíam, durante as implementações, o intuito observar as diferentes estratégias de resoluções dos alunos assim como a postura que deveria ser tomada pelo professor durante a realização das tarefas enquanto mediador. Como resultado, concluiu-se que as atividades ofereciam condições pedagógicas para o desenvolvimento de diferentes estratégias de resolução e que alguns aspectos técnicos, como resolução de imagens, necessitavam aprimoramentos.

Nunes (2011) investigou o processo de elaboração de atividades matemáticas por um professor pesquisador, nesse caso, o próprio autor. As atividades exploravam funções trigonométricas e foram desenvolvidas em colaboração com integrantes de um grupo de pesquisa. As tarefas eram desenvolvidas para serem exploradas com a utilização de uma calculadora gráfica. O material criado foi também implementado com alunos de graduação, na intenção de conhecer a opinião deste público quanto a dificuldade das atividades. Como resultado o autor enfatiza o desafio do professor em aprender e evoluir ao elaborar atividades com tecnologias e também destaca a importância de toda colaboração que recebeu durante o processo. A pesquisa aponta que o professor se submetendo a um processo de elaboração, como foi o caso, deixa de ser um mero reprodutor de atividades para aprender a pensar com tecnologia.

Assim como explicitado no presente estudo, notamos que a literatura evidencia a complexidade didático-pedagógica intrínseca ao processo de criação de uma atividade ou tarefa matemática. Além de questões conceituais referentes ao conteúdo matemático e nuances técnicas inerentes às potencialidades da 
tecnologia digital utilizada, questões epistemológicas e pragmáticas dos agentes educacionais envolvidos devem ser consideradas:

- Que teorias de aprendizagem ou perspectivas teóricas fundamentam a atividade?

- Qual o perfil educacional daqueles que explorarão a atividade?

- Qual o papel didático-mediador potencial do professor no desenvolvimento da atividade?

- Que informações devem ser explicitadas na tarefa de modo que existam indicações pertinentes a sua exploração mantendo-se o caráter investigativo?

Questões dessa natureza nortearam o desenvolvimento da presente pesquisa, cujo resultados apresentamos a seguir.

\section{Resultados e Discussão}

A análise qualitativa realizada acerca de aspectos fundamentais sobre o processo de elaboração das atividades matemáticas neste estudo está estruturada em duas temáticas principais: (1) Design: diz respeito a natureza investigativa das atividades e o público-alvo ou audiência em potencial; e (2) Tecnologias digitais e pensamento matemático: exploramos noções como visualização e experimentação-com-tecnologias para evidenciar as potencialidades do GeoGebra na produção de significados e conhecimentos matemáticos.

\subsection{Design}

A gênese de nosso processo criativo foi fundamentada em uma concepção sobre investigação matemática. Nossa intenção inicial era que as atividades tivessem um caráter investigativo, no sentido proposto por Ponte, Brocado e 
Oliveira (2013). De acordo com esses autores, um cenário de investigação matemática envolve:

- Reconhecimento da situação;

- Formulação de conjecturas;

- Realização de testes e refinamento de conjecturas;

- Demonstração e avaliação do trabalho realizado (provas, níveis de rigor).

Nesse sentido, tarefas abertas permitem várias maneiras de exploração, diferentes soluções e o surgimento de novas tarefas. Ponte (2005, p. 8) acredita que uma tarefa aberta "comporta um grau de indeterminação significativo no que é dado, no que é pedido, ou em ambas as coisas".

O referido autor sinaliza que atividades matemáticas, quando comparadas, possuem grau de desafio e estrutura que permeiam entre seus respectivos extremos. Isso quer dizer que o grau de desafio de uma atividade está situado entre os polos de desafio reduzido e desafio elevado. Por outro lado, a estrutura de uma atividade matemática varia entre as noções de atividades abertas e fechadas. Portanto, tarefas abertas têm sua importância no desenvolvimento do raciocínio matemático, tido que este baseia-se na relação rigorosa e estreita entre dados e resultados. Já as tarefas mais desafiantes são indispensáveis "para que os alunos tenham uma efetiva experiência matemática" (PONTE, 2005, p. 17).

A fim de contextualizarmos nossa análise no que se refere aos conceitos explicitados, apresentamos na Figura 1 a primeira versão da Atividade 5 elaborada pelo grupo de pesquisadores-autores.

Figura 1: Primeira versão da Atividade 5 
Atividade: Interseção entre planos e poliedros

a) Construa uma pirâmide e também um plano de maneira que suas duas construções se interceptem. Indique a figura gerada na interseção. Explore a ferramenta "interseção de duas superfícies" $\theta$.

b) Repita os procedimentos do item anterior, agora construindo um prisma. Explore agora o recurso "criar vista 2D de (...)" clicando com o botão direito sobre o polígono gerado pela interseção.

c) Você consegue estabelecer uma relação entre o número de faces do poliedro explorado e o número de lados do polígono gerado.

d) É possível obter triângulos, quadriláteros e pentágonos regulares a partir da interseção de planos com cubos? Justifique-se.

Fonte: Dados de Pesquisa

Em nossa análise, esta primeira versão está em consonância com o que Ponte (2005) classifica como atividade aberta, já que existe um grau de indeterminação no que é pedido. Esse design permite a exploração de diferentes estratégias de resoluções. Além disso, não são apresentados procedimentos "fechados" de construções. O primeiro item, por exemplo, pede a construção de uma pirâmide e de um plano, porém não expressa como estes podem ser construídos no GeoGebra. Em situações como essa, o grupo de pesquisadoresautores da atividade demostrou durante as reuniões uma inquietação fulcral como com relação a audiência. Ou seja: quem exploraria a atividade matemática? Sabíamos que o curso de extensão universitária seria destinado a professores (de matemática) e alunos de graduação (em matemática).

Além disso, a priori, seria um curso de introdução ao uso do GeoGebra. Mesmo com tal direcionalidade, questionamos: Quais seriam os conhecimentos prévios, matemáticos e tecnológicos, dos participantes? Eles teriam algum conhecimento sobre o GeoGebra? Teriam experiência e/ou familiaridade com a 
realização de construções dinâmicas com softwares? Quais seriam seus conhecimentos prévios sobre Geometria Espacial? Essas questões foram colocadas na primeira reunião por um dos pesquisadores, e tornou-se uma inquietação presente ao longo de todo processo criativo:

Pesquisador-autor: A gente não sabe se o curso será realmente de introdução. Será que o participante já usou o GeoGebra alguma vez? Os professores e alunos participantes do curso podem já estar bastante familiarizados com o GeoGebra.

Desse momento em diante o grupo esteve prontamente atento a contornar esse dilema. Pretendíamos conceber atividades em que o aluno não dependesse necessariamente de experiências prévias com o GeoGebra para realizá-las. Portanto a própria tarefa foi adquirindo gradualmente uma característica "tutorial". Por outro lado, queríamos que a atividade oferecesse questionamentos autenticamente desafiadores mesmo se os participantes, ou parte deles, já tivesse experiência com o GeoGebra. O caráter aberto/investigativo deveria ser preservado de alguma maneira. A busca por esse equilíbrio (pedagógico) no design das atividades, que envolve potenciais ações de mediação por parte dos professores, foi uma das principais características do processo criativo.

Na Figura 2 apresentamos parte do diálogo online entre os pesquisadores autores acerca do caráter tutorial do design das atividades.

Figura 2: Diálogo entre os pesquisadores no Facebook 


\section{5 de abril de 2016}

\section{Gente, eu estava revendo as atividades e pensando}

À respeito do "tutorial", penso que se formos colocar o passo a passo de tudo, vamos perder algumas ideias diferentes que poderiam surgir se não tivesse um direcionamento tão grande.

Se deixarmos as questões um pouco abertas, talvez surjam soluções diferentes, o que penso ser mais interessante do que pedir para eles seguirem uma "receita".

Creio que seria mais interessante fazermos um documento explicando para que servem as ferramentas do GeoGebra e disponibilizar para os participantes no primeiro dia de aula.

o que acham?

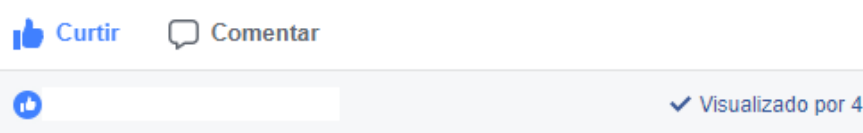

Eu acho que deveriam ter indicações em cada atividade... como a nova versão apresentada pela Rita. Acho que no futuro as atividades poderão ser investigadas separadamente por pessoas diversas. Cada uma deveria ter certa "autonomia" nesse sentido, sem depender de um tutorial a parte. Mas vcs decidem... o que acham? Curtir - Responder - 1 - 25 de abril de 2016 às 21:12

Só complementando... o "tutorial" deve ter certo caráter aberto. Ou seja, devemos buscar certa direcionalidade sem "fechar" o problema, mantendo a possibilidade de diferentes soluções/respostas, conjecturas, extensões, etc. Curtir - Responder - 25 de abril de 2016 às $21: 22$

Fonte: Dados de pesquisa

$\mathrm{Na}$ realidade, com a elaboração de várias versões das atividades, os pesquisadores-autores passaram a considerar que as atividades estavam demasiadamente fechadas, com uma característica tutorial prevalecente. Ponte (2005) considera que uma tarefa fechada é aquela na qual é claramente dito o que é dado e o que é pedido. Sendo assim, integrantes do grupo de pesquisadores expressaram suas opiniões apontando que as tarefas estavam guiando os alunos a todo momento, sem a potencial necessidade de mediação dos professores que trabalhariam com as atividades. A versão apresentada a seguir é aquela que foi implementada no curso de extensão.

\section{Atividade 5: Interseção entre Plano e Poliedros}

1) Clique no menu "Exibir" e então em "Janela de visualização 3D". Construa uma pirâmide da seguinte maneira:

a) Na janela 2D crie os pontos $A=(-1,0)$ e $B=(1,0)$. 
b) Na janela 3D clique em "Pirâmide" e depois em "Cubo" Construa o cubo clicando em B e depois em A.

2) Crie um plano da seguinte maneira:

a) Construa três controles deslizantes, com a ferramenta "Controle

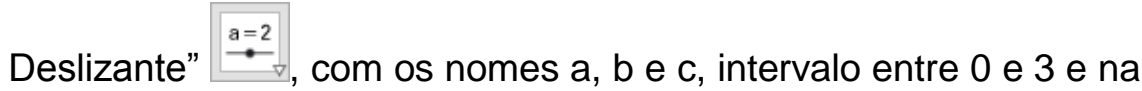
janela animação altere a velocidade para 3.

b) Na caixa de entrada insira os seguintes pontos $P=(-3,0, a), Q=$ $(0,3, b)$ e $R=(3,0, c)$.

c) Utilize a ferramenta "Plano por 3 pontos" $\stackrel{\bullet}{\bullet}$ e crie um plano clicando em $P, Q$ e $R$ que devem estar posicionados sobre as retas. Clique com o botão direito sobre cada controle e ative a função "Animar".

Sua construção deve se parecer com o mostrado na figura abaixo:

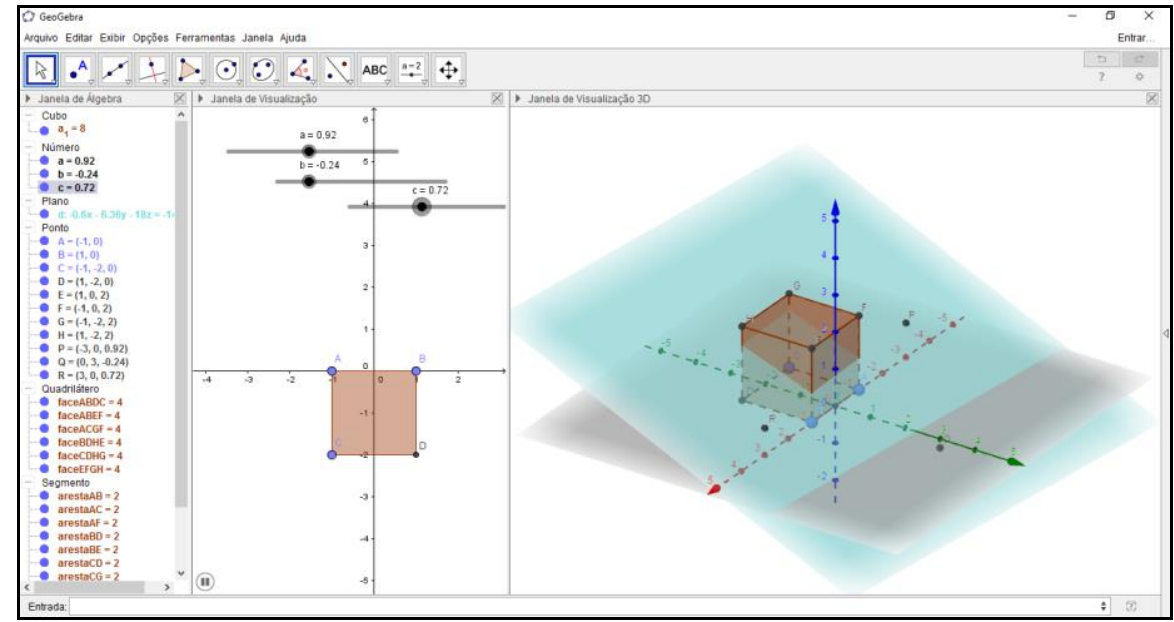

3) Selecione a ferramenta "Interseção de Duas Superfícies" e na janela de álgebra clique no cubo e no plano. O que você observa? Indique as figuras geradas pela interseção. Quantos lados tem o cubo? Quantos lados tem essas figuras?

4) Explore o recurso "criar vista $2 \mathrm{D}$ de (...)" clicando com o botão direito sobre o polígono gerado (dentro da tela de 3D ou na janela de álgebra) pela interseção. Neste momento uma nova janela a 
esquerda deve surgir. O que você observa? Esta janela confirma ou incrementa suas respostas o item 3 ?

5) Oculte o plano e os pontos, apague o cubo e em seu lugar construa uma pirâmide, acenda novamente o cubo e os pontos e ative a animação. Quantas faces possui a pirâmide? Quantas arestas possuem os polígonos gerados na interseção?

6) Você consegue estabelecer uma relação entre o número de faces do poliedro explorado e o número de lados dos polígonos gerados pela interseção entre o poliedro e plano em cada situação? Procure generalizar seu pensamento. Se achar necessário faça mais interseções com poliedros de sua escolha.

7) É possível obter triângulos regulares, quadrados, retângulos e pentágonos regulares a partir da interseção de planos com cubos? Como? Justifique.

Em nossa análise, nessa atividade, há um caráter tutorial no início com a apresentação de procedimentos para construção, principalmente nos itens (1) e (2). Em seguida, considerando a natureza das perguntas enunciadas, identificados questionamentos de caráter investigativo, que permitem a emergência de múltiplas resoluções e estratégias de resoluções, a exemplo do estímulo ao raciocínio, na busca pela relação de ordem trabalhada nos itens (6) e (7). Porém, como então classificar a atividade?

Ao mesmo tempo que esta visava atingir um caráter aberto, o cuidado com o grau de familiaridade com o GeoGebra que um aluno/professor poderia vir a ter (ou não) continuou a permear a elaboração. Dessa forma, a atividade adquiriu características que buscassem auxiliar o aluno no desenvolvimento, porém, ao mesmo tempo, buscassem deixar com que a descoberta fosse construída de maneira heurística, permitindo a elaboração e o teste de conjecturas. Dentro dessas características, consideramos que a atividade possui um caráter semiaberto.

A mesma caracterização foi proposta por Santos (2006), que relata o seguinte em seu trabalho: 
Busquei elaborar atividades que caracterizo não como abertas, mas semi-abertas, devido ao fato de apresentarem os passos para a construção, mas que possibilitassem a investigação e elaboração de conjecturas. Assim, o principal aspecto a ser considerado era a investigação e não a construção, apenas. (SANTOS, 2006, p. 62).

No caso da Atividade 5, as construções demasiadamente tutoriais foram retiradas do enunciado antes da versão final publicada. Porém, mesmo assim, o layout traz indicações de como explorar o material proposto, indicando como movimentar o plano através dos controles, propondo utilizar ferramentas que deixariam exposta a interseção gerada e também induzindo o surgimento da janela de visualização que destaca a seção em um plano bidimensional.

Portanto, outro aspecto fundamental relacionado ao design (investigativo) de uma atividade matemática diz respeito a maneira de utilização das potencialidades da tecnologia digital em cena. O caráter investigativo está relacionado ao caráter experimental.

\subsection{Uso de Tecnologias e Pensamento Matemático}

O caráter investigativo de atividades matemáticas baseadas no uso de tecnologias digitais perpassa por dois conceitos fundamentais: visualização e experimentação-com-tecnologias (BORBA; SCUCUGLIA; GADANIDIS, 2014).

De acordo com Borba e Villarreal (2005), um ambiente de experimentação está associado a formulação de conjecturas, coordenação de múltiplas representações, prova e demonstrações, tentativa e erro. Ou seja, essa perspectiva está em consonância com o entendimento denominado cenário de investigação matemática, proposto com Ponte, Broca e Oliveira (2003). Baseados na ideia dos autores acima, Borba, Scucuglia e Gadanidis (2014) salientam que atividades matemáticas elaboradas com base na noção de experimentação-com-tecnologias devem proporcionar o seguinte:

- criação e simulação de modelos matemáticos;

- geração de conjecturas matemáticas; 
- exploração de diversificadas formas de resolução;

- manipulação dinâmica de objetos construídos;

- realização de testes, conjecturas, utilizando um grande número de exemplos, modificando representações de objetos, simulando componentes de construções, etc;

- convencimento sobre a veracidade das conjecturas;

- elaboração de novos tipos de problemas e construções matemáticas;

- criação e conexão entre diferentes (e múltiplos) tipos de representações de objetos matemáticos;

- exploração do caráter visual, dinâmico e manipulativo de objetos matemáticos;

- incentivo a combinação de raciocínios intuitivo, indutivo e abdutivo, que podem contribuir ao desenvolvimento do raciocínio dedutivo;

- criação de atividades matemática "abertas controladas", ou seja, com direcionalidade ao seu objetivo;

- ensinar e aprender Matemática de forma alternativa;

- compreensão de conceitos; conhecimento de novas dinâmicas, formas de conectividade e relações de poder em sala de aula;

- envolvimento com um novo tipo de linguagem (informática) na comunicação matemática, além da escrita;

- criação de diferentes tipos símbolos e notações matemáticas;

- aprofundamento em vários níveis de rigor matemático; identificação de incoerências conceituais e/ou aprimoramento de enunciado. (BORBA; SCUCUGLIA; GADANIDIS, 2014, p. 51-52).

Uma atividade matemática pautada na experimentação-com-tecnologias pode não envolver, necessariamente, todos esses aspectos citados. No entanto, tais características são parâmetros relevantes para concebermos o que compreendemos como uma "boa" atividade matemática baseada no uso de tecnologias digitais. Portanto, o uso de recursos do GeoGebra como controle deslizante e a própria ideia de dinamicidade como a prova do arrastar oferecem meios para que se explore uma atividade matemática na perspectiva da experimentação. Vejamos uma situação na Atividade 5 (Figura 3):

Figura 3: Situação na Atividade 5 


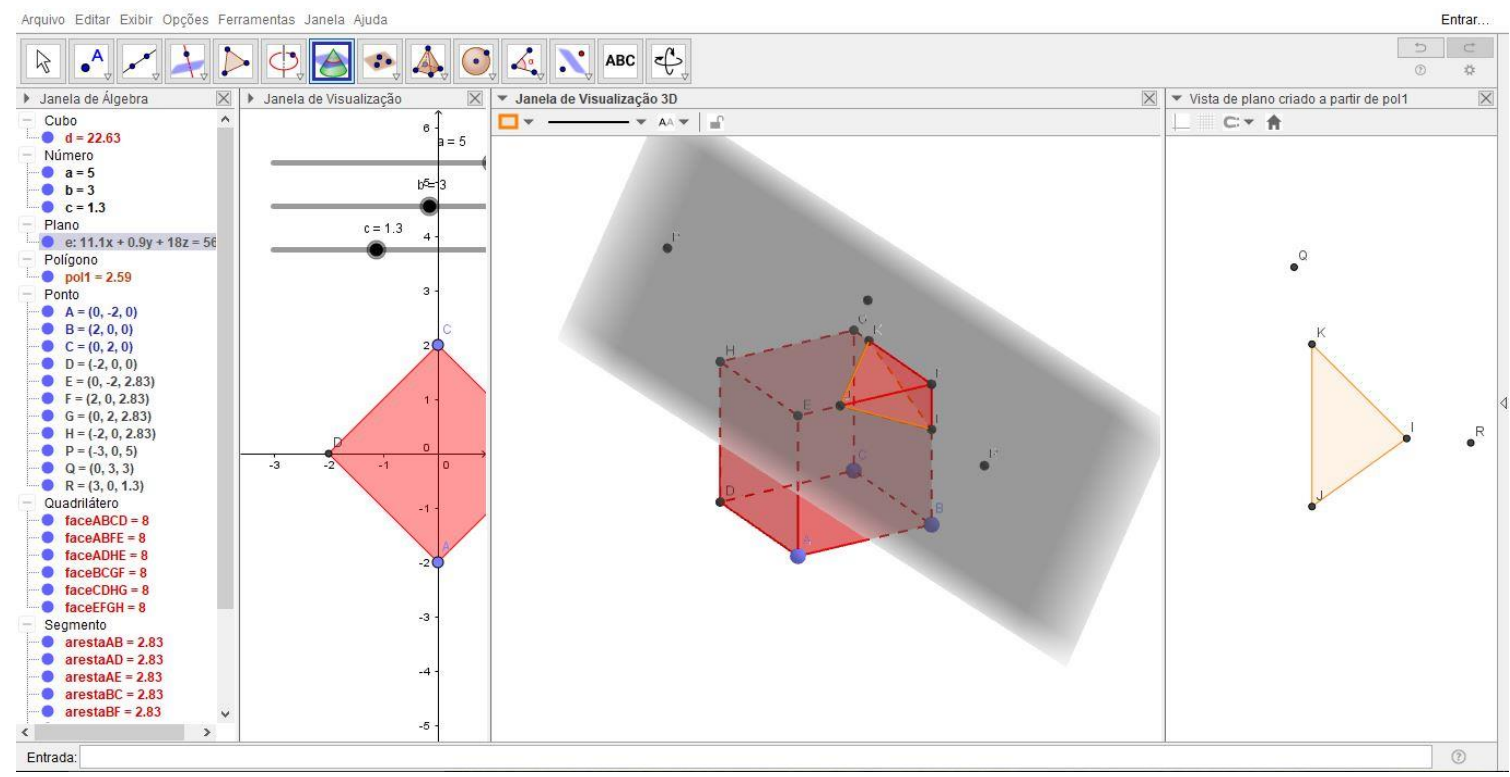

Fonte: Dados da pesquisa

Nessa situação identificamos potencial complexidade em termos de pensamento matemático. Trabalha-se com três controles deslizantes e diversas possibilidades de arrasto tanto na Janela 2D quanto na Janela 3D. Um simples movimento de qualquer um desses elementos gera uma alteração (complexa) de diversos outros elementos relacionados ou dependentes.

A compreensão acerca da natureza dessas relações diz respeito a produção de significados sobre o objeto matemático construído ou em construção. O estabelecimento de relações entre representações por meio da experimentação, que envolve elementos numéricos, algébricos, gráficos e espaciais, fomenta a aprendizagem nesse cenário.

É nesse sentido que Borba, Scucuglia e Gadanidis (2014) destacam o processo de pensar-com-GeoGebra como um aspecto significativo da aprendizagem matemática com tecnologias digitais. Notamos, portanto, a relevância na visualização do processo pedagógico. Durante as reuniões entre os pesquisadores-autores, discutiu-se o seguinte:

Pesquisador-autor: Existe algo aqui relevante em termos de complexidade na produção de significados. Há um modo de coordenar representações nesta situação que é complexo. 
Porque, geralmente, a gente trabalha com apenas uma janela de visualização, tudo bem? Faz aqui, aí compara: estou arrastando, está mudando algebricamente e está mudando a figura no visual. A gente vai coordenando isso, pensando matematicamente ao estabelecer relações entre representações. Aqui tem uma complexidade maior de visualização, pois são duas janelas, $2 \mathrm{D}$ e 3D. Então estamos coordenando múltiplas representações em dimensões diferentes. Isso é qualitativamente diferente do que tradicionalmente fazíamos apenas com a janela 2D do GeoGebra.

Lemos e Bairral (2010, p. 73) afirmam que "a visualização possui diversas definições e muitas das vezes está restrito à mente do ser humano". Os autores argumentam que a visualização tem foco na percepção e na construção de imagens visuais, ou seja, a manipulação de tais imagens.

Cifuentes (2005, p. 58) também sublinha que a intuição está ligada a visualização quando a firma que "o visual na matemática não deve ser entendido só em relação à percepção física, senão também a um certo tipo de percepção intelectual, ligada fortemente a intuição matemática”. Arcavi (2003, p. 235) destaca que

Hoje em dia, a centralidade da visualização na aprendizagem e no fazer matemática parece ser amplamente reconhecido. A visualização não é mais apenas para fins ilustrativos, mas também está sendo reconhecida como um componente chave do raciocínio (envolvendo profundamente o conceito e não o meramente perceptual), a resolução de problemas e até provando.

A questão da demonstração ou prova matemática foi também uma temática de discussão entre os pesquisadores-autores no processo de criação das atividades. Seja do ponto de vista investigativo (PONTE, 2005) ou experimental (BORBA; VILLARREAL, 2005), o design de atividades matemáticas deve fomentar aspectos referentes a prova matemática.

Scucuglia (2006), por exemplo, propôs uma atividade para explorar com calculadoras gráficas o Teorema Fundamental do Cálculo (TFC). Esse autor argumentou acerca da relevância de que estejam presentes no design na atividade matemática e na linguagem da própria tecnologia elementos simbólicos relevantes para a realização de uma demonstração algébrica. Ou seja, notações 
utilizadas e conjecturas emergentes no processo de experimentação podem/devem ser fundamentais para a compreensão e usufruto de notações matemáticas e artifícios ou procedimentos de demonstração essenciais em uma prova matemática. Em uma das reuniões, um dos pesquisadores-autores expressou a seguinte ideia acerca dessa temática:

Pesquisador-autor: Eu acho importante ter a demonstração, mas não pode ser assim: fez a experimentação e agora vou fazer a demonstração, de maneira totalmente segregada. A demonstração deve ser intrínseca a experimentação. Então, devemos pensar em como estabelecer essa relação, e isso depende dos desdobramentos com a relação as maneiras de exploração da atividade durante o curso; de elementos que podem surgir do ponto de vista simbólico e do ponto de vista dinâmico, os quais irão influenciar diretamente a prova algébrica a ser construída durante o curso.

Questões como o item (6) da Atividade 5 "Você consegue estabelecer uma relação entre o número de faces do poliedro explorado e o número de lados dos polígonos gerados pela interseção entre o poliedro e plano em cada situação? Procure generalizar seu pensamento. Se achar necessário faça mais interseções com poliedros de sua escolha", por exemplo, podem ser explorados de maneira algébrica. E tal exploração pode fomentar a enunciação e demonstração de natureza matemática.

\section{Conclusões}

Neste artigo discutimos aspectos relacionados à elaboração de atividades matemáticas com tecnologias, em particular, o GeoGebra. Este processo se mostra rico por evidenciar potencial pedagógico do material elaborado pelos pesquisadores-autores envolvidos na criação das tarefas nesta pesquisa.

Acreditamos que o processo de elaboração seja tão importante quanto o de implementação, pois, como apresentado em nossa análise, nele estão colocados os pareceres e as diferentes perspectivas de educadores enquanto sujeitos de 
pesquisa. A elaboração de atividades matemáticas com tecnologias requer conhecimento matemático a respeito do software utilizado. Ao mesmo tempo, é processo de aprendizagem e produção de novos conhecimentos por parte dos envolvidos.

Além disso, em nossa visão, as interações coletivas são de fundamental importância ao processo criativo. Estes são momentos em que um pesquisador interfere na produção do outro, acarretando em uma modificação de enunciado ou na utilização de diferentes recursos. Estas intervenções modificam qualitativamente a atividade que será proposta. Consideramos estes momentos como saltos qualitativos que delineiam e aprimoram o design da tarefa, visando proporcionar a investigação matemática e a experimentação com tecnologia. Contudo, a escolha do tema matemático a ser abordado e da tecnologia a ser utilizada influencia diretamente as discussões e o trabalho dos elaboradores.

De acordo com Borba, Scucuglia e Gadanidis (2014), tarefas matemáticas podem ser adaptadas ou reorganizadas, dependendo da manutenção ou reorganização de elementos estruturais do design. Como já existe uma grande quantidade de atividades elaboradas publicadas, cabe aos criadores realizar uma ampla revisão em bancos de dados, para referenciar corretamente a fonte na qual uma atividade foi obtida. Em nosso caso, buscamos criar originalmente as atividades ou então reorganizar ou adaptar seus designs fazendo a devida referência.

Por um lado, o desenvolvimento de atividades matemáticas com tecnologias mostrou-se um processo complexo, repleto de dialogicidade pedagógica e colaboração didática. Por outro, grande parte das pesquisas em Educação Matemática tem discutido aspectos acerca do processo de implementação e/ou desenvolvimento de atividades. Portanto, consideramos necessário o desenvolvimento de mais pesquisas que busquem discutir outros aspectos fulcrais sobre como ocorre o processo criativo de atividades matemáticas. 


\section{Referências}

ARCAVI, A. The hole of the visual representations in the learning of mathematics.

Educational Studies in Mathematics. V. 52, N. 3, p. 215-241, 2003.

BORBA, M. C.; SCUCUGLIA, R. S. R; GADANIDIS, G. Fases das tecnologias digitais em Educação Matemática: Internet e sala de aula em movimento. Coleção Tendências em Educação Matemática. Belo Horizonte: Autêntica, 2014.

BORBA, M. C.; VILLARREAL, M. E. Humans-With-Media and the Reorganization of Mathematical Thinking: information and communication technologies, modeling, experimentation and visualization. New York: Springer, 2005. v. 39.

CIFUENTES, J. C. Uma via estética de acesso ao conhecimento matemático. Boletim GEPEM, n. 46, p. 55-72, jan/jun 2005.

GORGORIÓ, N.; ARTIGUES, F.; BANYULS, F.; MOYANO, D.; PLANAS, N.; ROCA, M; XIFRÉ, À. Proceso de elaboración de atividades geométricas ricas: un ejemplo, las rotaciones. Suma. Badalona, 33, 57-71. Fev 2000. Disponível em

<http://www.abed.org.br/congresso2004/por/pdf/049-TC-B2.pdf>. Acesso em 26 de mar 2017. >. Acesso em 26 de mar 2017.

LEMOS, W. G.; BAIRRAL, M. A. Poliedros estrelados no currículo do ensino médio. 1 ed. Rio de Janeiro: Ed. da UFRRJ, 2010.

MARSHALL, M. N. Sampling for qualitative research. Family Practice, V.13, n. 6, p. 522526,1996

NUNES, J. A. Design Instrucional na Educação Matemática: Trajetória de um professor de Matemática que elabora atividades sobre funções trigonométricas com a calculador HP 50G. 2011. 171 f. Dissertação (Mestrado em Ensino de Ciências e Matemática), Universidade Luterana do Brasil, Canoas, 2011.

PONTE, J. P; Gestão curricular em Matemática. In GTI (Ed.) O professor e o desenvolvimento curricular, Lisboa: APM, 2005.

PONTE, J. P.M.; BROCARDO, J.; OLIVEIRA, H. Investigações matemáticas na sala de aula. 3 ed. Belo Horizonte: Autêntica, 2013.

SANTOS, S. C.; A produção matemática em um ambiente virtual de aprendizagem: O caso da Geometria Euclidiana Espacial. 2006. 145 f. Dissertação (Mestrado em Educação Matemática) - Instituto de Geociências e Ciências Exatas, Universidade Estadual Paulista "Júlio de Mesquita Filho", Rio Claro, 2006.

SCUCUGLIA, R. R. S. A Investigação do Teorema Fundamental do Cálculo com Calculadoras Gráficas. 2006. 145 f. Dissertação (Mestrado em Educação Matemática) Instituto de Geociências e Ciências Exatas, Universidade Estadual Paulista "Júlio de Mesquita Filho", Rio Claro, 2006. 